\title{
A consideration of copulatory behavior and activity level as reinforcement of female rat behavior
}

\author{
PETER O. PERETTI \\ Kennedy-King College, 6800 South Wentworth Avenue, Chicago, Illinois 60621 \\ and \\ KENNETH BRUMMEL \\ Illinois Benedictine College, College Road, Lisle, Illinois 60532
}

\begin{abstract}
In studies of copulatory behavior between rats, it has been found that copulation can have a reinforcing effect on the male animal. This effect on the female rat is in question. The present study attempted to determine if copulatory behavior was reinforcing for the female rat: (1) when comparing estrous and diestrous Ss, and (2) when comparing sexual aggressiveness or sexual passivity of the male mate. Results suggested the possibility of reinforcement for estrous rats, although, due to the measure used, the results might have been influenced by the general activity of the animal. The results with active and passive Ss tend to support this conclusion.
\end{abstract}

In the copulatory behavior of the rat, the male usually appears to take the initiative. It is therefore convenient to organize the behavioral description around the responses of the male, which may be why most of the research has been done in this area (Bermant, 1967).

When a male rat with previous copulatory experience and a receptive female are placed together, within a minute the male normally begins the preliminaries to copulation. This could be nothing more than a brief nuzzling of the female's flank or genital area.

Through these preliminary actions, a receptive female will go into short, jerky, forward motions and a lordosis response. This lordosis response is that which allows the rats to copulate. Lordosis is an arching of the back that produces a pronounced elevation of the hindquarters and the genital area. The response is not under voluntary control of the female, but is, rather, a reflex response which occurs when the male grasps the female's flanks. This is the only condition in which the female is the passive member of the pair.

There is evidence that suggests that copulation can reinforce instrumental learning in the male rat (Kaufman, 1953; Kagan, 1955; Beach \& Jordan, 1956), but the question remains whether the same is true for the female rat.

Bermant (1961) and Pierce and Nuttall (1961) found that estrous female rats could be trained to perform an arbitrary response if that response was followed by the presentation of the male rat and subsequent sexual contact. However, Bolles, Rapp, and White (1968) believed that all the data really indicated were that when the female was allowed to control contact with the male, her latency to make an instrumental response varied inversely with the completeness of the male's sexual contact.

Pierce and Nuttall (1961) suggested that mating had an appetitive quality which supported the idea that more complete sexual contact was not as reinforcing as less complete contact.

In studies concerning the idea of penile sensory feedback, Bermant and Adler (1966) found that partial penile sensory deprivation affected capacity for sexual performance, while leaving sexual arousal intact. Other studies done in this area were: surgical anesthesia of the genital region (Cooper \& Aronson, 1962), morphological abnormalities of the penis (Beach \& Holz, 1964), and motor disturbances in the genital area (Kagan, 1955). All of these studies have suggested a lack of penile feedback affecting sexual responding adversely.

This research was conducted to attempt to find out if copulatory behavior was reinforcing for the female rat. It centered around estrous and diestrous female Ss as well as aggressive and passive males. Two null hypotheses were tested: (1) If estrous and diestrous female rats were allowed to run to a male rat, then there would be no difference in the running time. (2) If estrous and diestrous female rats were allowed to run to either a sexually aggressive or a sexually passive male rat, then there would be no difference in the selection of each.

\section{METHOD}

\section{Subjects}

Ten female and 10 male mature Sprague-Dawley rats, about 135 days old, were used as Ss. They were given water and food ad lib (Wayne Lab Blox pellets) in their home cages. All animals were individually housed for the entire preresearch period.

\section{Apparatus}

A straight maze, $62.82 \times 8.95 \times 8.95 \mathrm{~cm}$, was used. The female rat ran the straight runway to get to a male rat in the goalbox. The maze was covered by a transparent plastic top, which allowed the rats to be observed at all times.

The starting box was $10.26 \times 8.95 \times 8.95 \mathrm{~cm}$. It had two slide openings; the rear opening allowed the rats to be placed in the 
Table 1

Mean Time (Seconds) for Females in Leaving the Starting Box and Running the Straight Maze and for Male Approach to Female

\begin{tabular}{|c|c|c|c|c|c|c|}
\hline \multirow[b]{2}{*}{ Ss } & \multicolumn{2}{|c|}{ Latency } & \multicolumn{2}{|c|}{$\begin{array}{c}\text { Running } \\
\text { Time }\end{array}$} & \multicolumn{2}{|c|}{$\begin{array}{c}\text { Male } \\
\text { Approach }\end{array}$} \\
\hline & E & D & $\mathrm{E}$ & D & E & D \\
\hline 1 & .76 & 1.07 & 2.86 & 3.66 & 31.9 & 34.0 \\
\hline 2 & .88 & 1.42 & 3.18 & 4.20 & 27.6 & 36.8 \\
\hline 3 & .81 & 1.31 & 2.76 & 2.56 & 23.6 & 41.7 \\
\hline 4 & .89 & 1.71 & 2.82 & 3.44 & 24.8 & 29.1 \\
\hline 5 & .85 & 1.50 & 2.10 & 3.75 & 25.0 & 41.0 \\
\hline
\end{tabular}

$E=$ estrous, $D=$ diestrous

$t$ test for latency time in leaving the starting box between estrous and diestrous females: $t=5.071, d f=8, p<.001$. Chi square for movement toward an aggressive or passive male between estrous and diestrous females: $\chi^{2}=0.44, d f=1, p>.05$.

box; the forward opening allowed the animals access to the runway. The slides were made of heavy cardboard.

The runway followed directly into a cubicle or goalbox, 25.64 $\mathrm{x} 20.51 \times 28.21 \mathrm{~cm}$. A glass barrier between the runway and the goalbox allowed the female to see the male rat in the area. Entry into the goalbox was covered by an appropriately sized screen lid which could be removed easily and allowed quick access to the animals.

A Y-maze was also used in which the female rat could see one aggressive male and one passive male rat at each end. There was a starting box, $10.26 \times 8.95 \times 8.95 \mathrm{~cm}$. The box was covered with a transparent plastic top. It had two slide openings: the rear opening allowed the rat to be placed in the box; the forward opening allowed the rat access to the runway. The slides were made of heavy cardboard.

The base of the Y-maze was $62.82 \times 8.95 \times 8.95 \mathrm{~cm}$. Both arms of the maze were $56.41 \times 8.95 \times 8.95 \mathrm{~cm}$. The total distance between the startbox and the goalbox which the rat had to travel was $119.23 \mathrm{~cm}$ in either direction. The same type of boxes were used in this apparatus as in the straight maze.

A stopwatch was used to measure running time in seconds, as well as the latency, or the time in seconds before a female left the startbox.

\section{Procedure}

Ten female and 10 male Sprague-Dawley rats were selected randomly from the colony of animals inbred in the laboratory. They were fed and watered on an ad lib schedule since birth. Five female Ss were brought into estrous by subcutaneous injections of $0.1 \mathrm{mg}$ estradiol benzoate $24-30 \mathrm{~h}$ before testing and $1.0 \mathrm{mg}$ of intramuscular progesterone $4-6 \mathrm{~h}$ before testing. The drugs were used to induce estrous so that all animals might be tested in the same way at about the same time. Female rats were determined to be in estrous if they had reached Stage 10 of the Hemmingsen test for sexual arousal (ear vibration and lordosis produced by digital stimulation of the genital region).

Male rats were maintained on normal feeding and watering on ad lib schedules. Since they were nocturnal animals, it was assumed that performance might be enhanced at night; therefore, all testing was begun at 9:00 p.m. The laboratory was also least used and most quiet at this time.

Two weeks before testing, the rats were paired (one male and one female) in cages for a period of 10 days. It was assumed that the female would be in estrous at least once during this time and, hence, that all animals were sexually experienced. This assumption was confirmed by observation.

\section{Experiment 1}

Each of the five estrous females was given pretrial periods in which to explore the runway and goalbox and become familiar with the straight maze. Each female was then placed in the startbox of the same maze, while a male, chosen randomly from the 10 available, was placed into the goalbox. Females were timed, and the following were recorded: (1) latency of female to leave the startbox, (2) running time of female through the maze, and (3) time taken by the male to approach the female in the goalbox.

When the female was near the goalbox, the partition was removed. After the first mount by the male, the female was removed. The second female was put in the startbox and the same procedure followed. All five females were tested in order. A different male was used on every trial. Females were run about $10 \mathrm{~min}$ after the removal of the previous experimental animals. During this period, the maze was wiped with a clean cloth to remove any debris which might influence the behavior of the following animals. A total of eight trials for each of the five females were run.

Five diestrous females were run; the procedure was the same as for the estrous group. At the completion of the total of eight trials, the animals were returned to their home cages.

\section{Experiment 2}

On the basis of the speed of response to the female in the 10-day pretrial period and the number of contacts made, the five males which responded most and made the greatest number of contacts were considered sexually aggressive. The five males making the fewest contacts were designated as sexually passive.

Five estrous and five diestrous females were familiarized with the Y-maze. It was observed that there was no consistent tendency by these animals to prefer either right or left turns. At the beginning of each trial, an aggressive male was placed on the right side and a passive male was placed on the left. The female was placed in the startbox. Four subsequent trials were made with the same female; the aggressive male was on L-R-L-R-L-R-L (alternate) sides.

Once the female was close to the goalbox, the glass partition was removed. Females were removed from the maze after one intromission was made by the male.

Four consecutive trials were run on each occasion for the five females, with $10 \mathrm{~min}$ between each trial. The male performed more than four consecutive trials during one testing period.

\section{RESULTS}

The results from the measurement of latency, running time, and approach by male to female in the straight maze can be seen in Table 1 .

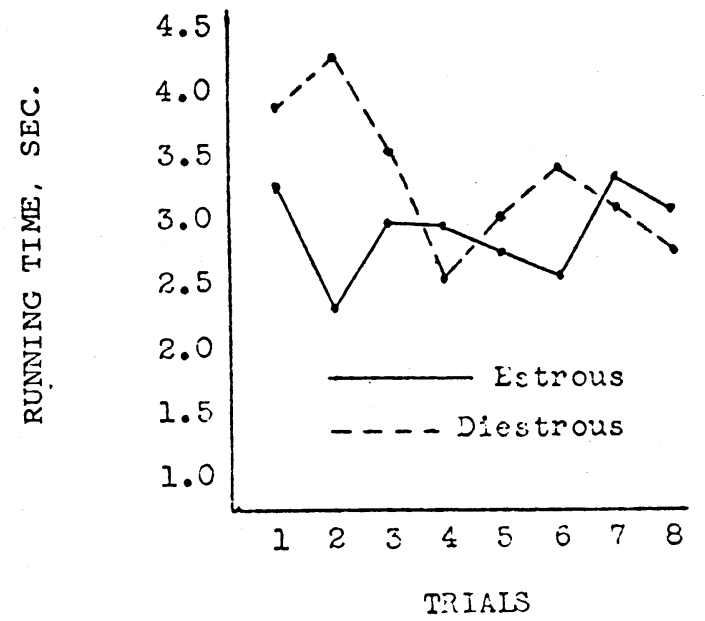

Fig. 1. Mean running time for each trial. 


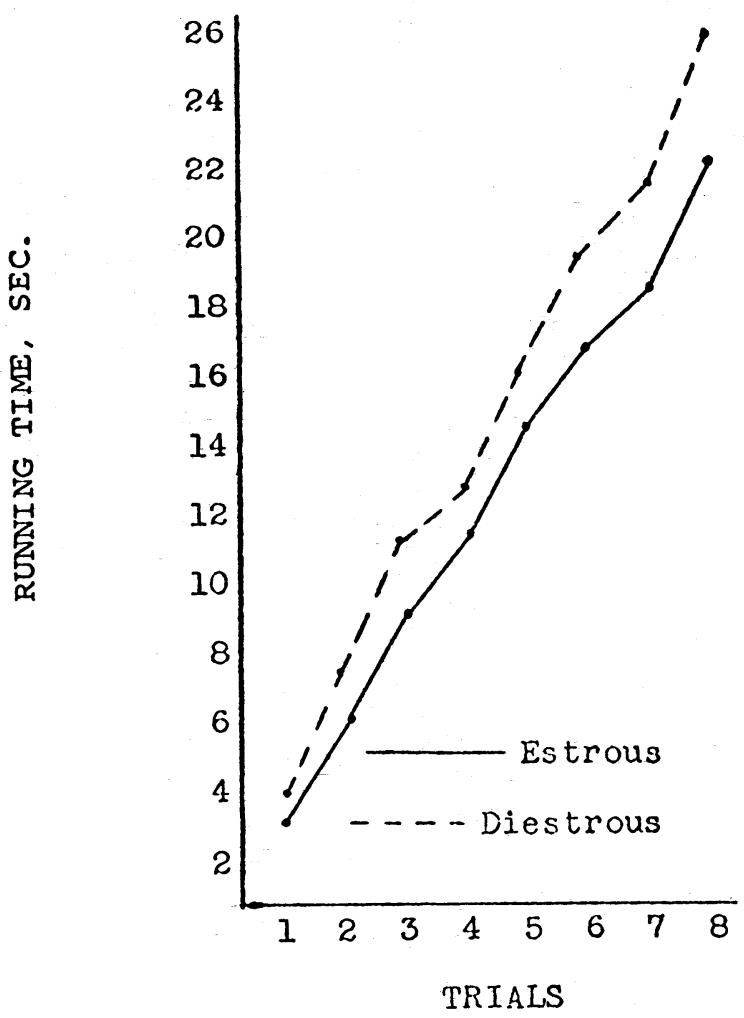

Fig. 2. Cumulative average running time for each trial.

A t test was calculated for latency time in leaving the startbox between the estrous and diestrous females. The $\mathrm{t}$ was calculated to be $\mathrm{t}=5.071, \mathrm{df}=8, \mathrm{p}<.001$, and it was indicative of a significant difference between the two groups of Ss.

A chi square was calculated on the choices of the estrous and diestrous Ss to move toward an aggressive or passive male $S$. The result, $\chi^{2}=0.44, \mathrm{df}=1, \mathrm{p}>.05$, suggested no significant difference between the two groups.

Figure 1 shows the mean running time for each trial. Figure 2 indicates a cumulative average running time for each trial. The estrous females took less time and moved down the runway faster than the diestrous female Ss.

\section{DISCUSSION AND CONCLUSIONS}

The estrous-diestrous variation was used to evaluate the effects of estrous on fluctuating responsiveness of female laboratory rats to males. The choice given the female Ss between active and passive males was introduced to assess the effect of male behavior itself upon the reinforcing effect of sexual contact.
Estrous Ss performed better than diestrous Ss. When females are in estrous, copulatory behavior tends to be more reinforcing for them than when females are in the diestrous condition. In addition, females in estrous approach a male faster than do females in the diestrous condition. The former animals learn the maze and the location of the males more quickly than do the latter females. This finding suggests the facilitation of certain learning tasks for the estrous females when reinforced by copulation. It also suggests, however, that during estrous there is a general rise in the activity level of the female Ss which tends to enhance performance.

The level of male performance, aggressive or passive, did not tend to influence significantly the behavior of the female, regardless of an estrous or diestrous condition. A basic property of the males which influenced responsiveness of females was simply the ability to copulate. Copulation with the male tended to produce the most active and responsive female. This responsiveness might have resulted from the increase in the general activity level of the female $S$ during copulation. The act of intromission by the male might also be said to have been positively reinforcing for the female as it tended to enhance subsequent performance.

\section{REFERENCES}

Beach, F. A., \& Holz, L. Effect of intromission without ejaculation upon sexual behavior in male rats. Journal of Comparative \& Physiological Psychology, 1964, 52, 476-481.

Beach, F. A., \& Jordan, L. Effects of sexual reinforcement upon the performance of male rats in a straight runway. Journal of Comparative \& Physiological Psychology, 1956, 49, 105-110.

Bermant, G. Response latencies of female rats during sexual intercourse. Science, 1961, 133, 1771-1773.

Bermant, G. Copulation in rats. Psychology Today, 1967, 33, 33-41.

Bermant, G., \& Adler, C. Sexual behavior of male rats: Photographic analysis of the intromission response. Psychonomic Science, 1966, 2, 65-67.

Bolles, R. C., Rapp, H. M., \& White, G. C. Failure of sexuality activity to reinforce female rats. Journal of Comparative \& Physiological Psychology, 1968, 65, 311-313.

Cooper, R. T., \& Arorison, G. P. Nonspecific stimulation and sexual behavior in the male rat. Behaviour, 1963, 20, 110-114.

Kagan, J. Differential reward value of incomplete and complete sexual behavior. Journal of Comparative \& Physiological Psychology, 1955, 48, 59-64.

Kaufman, R. S. Effects of preventing intromission upon sexual behavior of rats. Journal of Comparative \& Physiological Psychology, 1953, 46, 209-211.

Pierce, J. T., \& Nuttall, R. L. Self-paced sexual behavior in the female rat. Journal of Comparative \& Physiological Psychology, 1961, 54, 310-331.

(Received for publication January 18, 1973; revision received March 21, 1973.) 